\title{
ЗВУКОВОЙ ОБРАЗ «В ЛАНДШАФТЕ», НЕПОСРЕДСТВЕННЫЙ И ИММЕРСИВНЫЙ
}

\author{
Н. Н. Сосна \\ Институт философии Российской академии наук, Москва, Россия \\ phljrnl@yandex.ru
}

В статье рассматриваются возможности подхода к образу не только через область визуального. Указывая на звуковую материю как дополнительный источник образов, автор отмечает, с одной стороны, зависимость sound studies от визуальных исследований: методологические ходы, связанные с миметическим выделением пар терминов «слышать/слушать», «слышимое/неслышимое» (подобные «смотреть/видеть», «видимое/невидимое»); расширение предметного поля за счёт включения примеров исподьзования звука, которые не рассматривались в истории и теории музыки (подобно тому, как история и теория искусств практически не рассматривала примеры, предшествовавшие складыванию живописного канона или появившиеся после его трансформации). С другой стороны, автор демонстрирует, как не отягощённые миметизмом визуального экологические sound studies, уравнивающие слушателя-человека с любыми объектами окружающего пространства в качестве препятствия на пути распространения звуковых волн, попутно существенно сужают возможность говорить об образе. Акцентируя безусловно важные характеристики звукового воздействия - иммерсивность и непосредственность, эти исследования подводят к выводу об отсутствующих столкновениях и специфических констелляциях, результатом которых мог бы быть образ. Выбранные для примера эксперименты Х. Ноака призваны показать, как нетипичный художественный жест, не отрицающий значимость «природы», раскрывает раздичные каналы восприятия навстречу друг другу и является генеративным в отношении констелдирующих эффектов вспыхивания образа.

Кдючевые слова: образ, звуковой образ, sound studies, экология, шум, иммерсивность, констелляция, музыка.

\section{SOUND IMAGE "IN A LANDSCAPE", IMMEDIATE AND IMMERSIVE}

\author{
Nina Sosna \\ Institute of Philosophy, Russian Academy of Science, Moscow, Russia \\ phljrnl@yandex.ru
}

The article aims to investigate if there are possibilities to put questions of image beyond the field of the visual. Considering the sonic matter as 
a complementary source of images, the author demonstrates, on the one hand, the dependence of sound studies on visual studies. It can be seen in methodology that uses a pair of terms 'hearing / listening', 'audible / unaudible' similar to 'look / regard', 'visible / invisible', as well as in expansion of the subject field by including examples of dealing with sound beyond the frame of classical music theory. On the other hand, ecologically charged sound studies developing out of communication with visual studies, that equate a human listener with any object standing in the way of sound waves, diminish the possibility to speak about image. These studies emphasize the main characteristics of the impact of the sonic - immersion and immediacy, but at the same time accentuate the absence of tensions and specific constellations, the result of which could be an image. Contrary to the latter, Hunter Noack's actions exemplify by means of a "natural" artistic gesture the opening of different sense perceptions one to the other in their generative functions to flash images.

Keywords: image, sound image, sound studies, ecology, noise, immersion, constellation, music.

DOI 10.23951/2312-7899-2020-1-47-57

Понятийное определение образа возникает на пересечении нескольких объёмов: чувственных данных, которые, в свою очередь, привязаны к разным типам восприятий, задействуемых разными органами чувств; (абстрактной) мыслительной деятельности; материадьных единиц. Отсюда очевидно, что возможно говорить о множествах образов, причём эти множества можно выделять на разных уровнях: визуальные и сонорные, образы-схемы и образы-движения, типографические и акеропита. Не располагающий чётким статусом образ тем не менее представдяется некоторым единством, каждый раз спазматически, стохастически захватывающим это мгновенное объединение материального и нематериального.

Такая специфическая «природа» образа в большей степени провоцирует возникновение скорее синтетических, мультимодадьных и других видов метододогий, нацеленных при исследовании образа на работу с объектом «смешанным», чем «чистым». Это, в свою очередь, заставляет исследователей утверждать, если перефразировать название статьи У. Митчелла, что «чистых образов не существует», ибо смешивание, приведение к коммуникации разных уровней, разных фигур, разных позиций видится как главнейшая функция образа.

Однако представдяется, что выделение и описание специфического кластера в этой неясной области образов, очерчивающего 
именно образы, связанные со звуковой материей, должно как сделать более чёткими раздичия между типами образов и способами их производства для более последовательного оперирования ими, так и способствовать выделению более чётких характеристик образа в целом.

Рассмотреть эту область важно по причине специфичности звука, обладающего особенными характеристиками распространения, фильтрации и воздействия. В значительном корпусе работ, исследующих звуковые взаимодействия с позиций музыковедческого анализа, или фокусирующихся на мультимедийных эффектах ${ }^{1}$, или разрабатывающих программы soundscapes ${ }^{2}$, сегодня выделяется набор подходов, направленных на выяснение постгуманистических ресурсов - от сравнительно мягких [Voegelin 2010, 2014] до более жёстких [Thompson 2017]. В этих последних звуковая материя рассматривается как зона непосредственного разворачивания до-, внеили постантропоморфных способов связи с окружающим пространством. Показательно, что именно звуковые, а не визуальные взаимодействия оказываются вписанными в важную экологическую парадигму современности [Hoerl 2007].

Чтобы показать, что означают эти актуальные разработки для исследования образа, обратимся сначала к общим описаниям образа, с одной стороны, постулирующим не искдючительно видимый способ появдения образов, однако концентрирующимся именно на связи визуального и образного, с другой. Приходится признать, что объём исследований, посвящённых визуальному образу, даже сегодня намного превышает число тех, что посвящены звуку. Так, в программной статье Ж-Л. Нанси, открывающей книгу об образах [Nancy 2003], читаем, что образ может быть не только видим, но также слышим. Нанси даже завершает эту статью нотной записью. И в целом он выстраивает рассуждение о том, что такое образ в принципе, признавая и материальность образа («Образ всегда материален, у него есть определённая масса, вес, границы» [Nancy 2003, 62]), и раздичие искусств в отношении тех органов чувств, к которым каждое из них преимущественно апелдирует [Nancy 2001, 12-16]. Однако если Нанси исподьзует примеры, то чаще всего они отсылают к живописи или кино.

\footnotetext{
${ }^{1}$ Прежде всего имеются в виду работы, анализирующие соотношение изобразительного и звукового в кино, как, например, в проекте М. Шиона [Chion 1990]; но также исследования, рассматривающие сочетания текстуального и звукового, что имеет уже достаточно додгую традицию в области иитературоведения.

2 Программа сформулирована М. Р. Шефером [Schafer 1977] и продолжена далее П. Оливеpoc [Oliveros 2010].
} 
М.-Ж. Монзэн, со своей стороны, занимаясь вопросом истоков нашего отношения к образам и даже отдельно разбирая роль звучащего слова (конечно, в особом контексте и весьма широко понимаемого), тем не менее удаляясь в истории так далеко, как датируются рисунки пещеры Шовэ [Mondzain 2010], и пытаясь представить себе, как же эти рисунки были сделаны, как смешивались краски, как прищуривались глаза и т. д., снова говорит об образе, обращённом прежде всего к глазам. Для описания действия образов ей оказываются также необходимы «места сборки» суждений о видимом, которые способствуют опредедению смысла того, что видят раздичные участники процесса и которые Монзэн обозначает как «тончайшую плёнку» или «вуаль». В принципе их не обязательно наделять материальными характеристиками, однако их присутствием обозначено опосредованное воздействие видимого.

Можно быдо бы привести ещё множество примеров, но здесь даже важнее обратить внимание на эффекты, которые эти интереснейшие исследования косвенно оказали на изучение звуковой ткани. На разных уровнях, в том числе операциональной терминологии, нередко воспроизводится аргументация, выстроенная для обиасти видимого. Так, выкристаллизовавшейся в рамках визуальных исследований паре понятий gaze/regard уподобляется выделение пары понятий hearing/listening ${ }^{3}$, также обозначающей разные типы активности разной степени увлечённости; по аналогии с видимым/ невидимым выделяются слышимое/неслышимое, и выделяются они тоже в связи со способностями чедовека, а также пороговыми ведичинами его восприятия.

Ещё один эффект - это «контекстуадизация», иди «заземление»: так же, как для оформления подхода visual studies было принципиально исследовать не тодько рисунок, живопись, скульптуру, архитектуру - традиционные жанры для истории искусства в его западном понимании, но и вотивные фигуры, и формы кристаллов, так и для sound studies важно было научиться критически исподьзовать раздичие между «звуком» и «музыкой», подчёркивая, что последняя - это только часть звуков, организованных приятным, гармоническим для человеческого уха образом. Так обрели свои полномочные права не только musique concrete, но и раздичные «шумы»: «бедый», «коричневый». Продуктивно поэтому представить себе, как могло бы выгдядеть исследование, анадогичное пионерской работе

\footnotetext{
${ }^{3}$ Listening связывается с направленными и нередко технически усиленными попытками раздичать и интерпретировать слуховые ощущения, тогда как hearing представдяется пассивным протеканием звуков через уши.
} 
Х. Бельтинга об «образах до эпохи искусства» [Бельтинг 2002], которое было бы посвящено звукам, дополнительным как музыке предшествующих эпох, так и саунд-арту настоящего времени. Отчасти эти функции выполняет работа В. Мартынова о принципиально не-композиторской музыке (но всё ещё музыке), о роли церковного пения и т. д. [Мартынов 2005].

При этом перестраивании на другой масштаб звукового материала возникает двоякая проблема: как, с одной стороны, учитывать разный звук (в том числе необработанный для человеческого уха), но, с другой стороны, делать это таким образом, чтобы поле исследований оставалось структурированным, по возможности не аморфным. Очевидно, что для этого необходимо также указывать структурирующие элементы. История идей знает немало примеров расширения предметного подя для вновь вводимых методологий, что нередко приводило к частичной потере операбельности понятий. Так, эксперименты с синестезией в русском авангарде начала XX в. обещали революцию в восприятии зрителей и участников: они предполагали целиком вовлекать их в действо, которое должно было перевернуть организацию их чувственности настолько, что выходить после окончания представления зритеди должны были совершенно другими дюдьми. «Поэма экстаза» Скрябина, мультимедийные, как сказади бы сегодня, постановки Матюшина и т. п. создавались именно с этой целью. Какие реальные эффекты произвели эти проекты? По разным причинам они часто оказывались меньше ожидаемых [Lista 2006]. Продвинули ли они размышления о чувственности, в том числе звуковом восприятии, дадьше? Безусловно. Была ли «материальная база» для их осуществления в техническом отношении недостаточной? Возможно.

Другой пример - новаторские теоретические разработки М. Мерло-Понти, связанные с исподьзованием понятий «хиазм» и «Плоть мира». С одной стороны, они были призваны возвысить восприятие (прежде всего визуальное, но не только: тактидьные ощущения, касание как более общий принцип, объясняющий процессы взаимодействия, уже присутствуют в его текстах) до фактически космического уровня, указывая на область, из которой индивидуализируется субъективность, что весьма созвучно актуальным исследованиям наших дней. С другой стороны, и сразу после публикации его работ, и сейчас многие специадисты высказывают иди сомнения в том, что настодько общими понятиями можно эффективно пользоваться, или вовсе раздражение от того, что в попытке следовать Мерло-Понти требуется фактически вывернуться 
наизнанку, чтобы и анализировать процессы, происходящие «внутри», и регистрировать события, случающиеся вокруг, «вовне», лавируя между двумя противоположностями [Rogozinski 2002].

Перед тем как формулировать, чем именно звуковая материя может быть интересна в принципе и чем она актуальна сегодня в области исследований образов, обратимся к одному примеру из области художественных проектов, развивающихся сейчас, что позволит сразу выделить несколько принципиальных характеристик, поскольку проект этот достаточно типичен.

Речь идёт о многократных акциях Х. Ноака в рамках проекта «In a Landscape», чьё название отсылает к одноимённой работе Д. Кейджа. Ноак (Hunter Noack) - профессиональный музыкант, пианист, исполнитель классического репертуара, который в какой-то момент выступил с инициативой устраивать концерты на открытом воздухе. И не где-нибудь, а в его родном Орегоне, в спектакулярных и часто всё ещё почти диких природных ландшафтах этого штата. При поддержке частных фондов, обеспечивающих транспортировку необходимого оборудования. Частично для местных жителей (нередко впервые оказывающихся на подобном мероприятии, связанном с классической музыкой), поскольку это один из принципов организации - приглашать тех, кто именно происходит из этой местности (как и сам Ноак), и только отчасти - для меломанов, завсегдатаев обычных концертных залов.

Фотографии этих мероприятий впечатляют: Ноак за роялем на небольшом возвышении посреди песчаной пустыни, с вырисовывающейся в звенящей дали нагретого воздуха горной цепью, и ничего вокруг, никаких следов цивилизации (Alvord desert). Ноак на фоне пышной растительности вокруг озера, и снова вокруг только зелень (Playa). Единственный технический «трюк», который Ноак раз за разом использует, помимо тех «естественных шумов», с которыми ему приходится иметь дело - вроде ветра, температурных условий и т. д. - это наушники, которые получает каждый участник концерта. Иначе говоря, звук исполняемого произведения одновременно разносится по воздуху и подаётся в наушники. Причём крайне дюбопытно, что, по словам Ноака, в начале концерта часть слушателей сидит без наушников, но к концу концерта наушники надевают все. Это означает, что каждый слушатель - в зависимости от своего уровня восприятия, состояния, уровня знакомства с классической музыкой, ощущений от разворачивающегося пейзажа и прочих факторов - имеет свой собственный комплексный образ происходящего. И эта комплексность усиливается тем, что окружающий пей- 
заж он только видит, будучи отрезанным от звуков этого пейзажа наушниками, и обратно, возможный образный ряд, который могла инициировать музыка, фактически отменяется «природой», заступающей на его место.

Сам Ноак говорит о том, что этот его проект «позволяет слушателям получать удовольствие от классической музыки на лоне природы, а не ограничивать себя формальными рамками концертного зала» ${ }^{4}$. К чему ведёт подобное изменение контекстов и их новое специфическое сочетание? Ноак полагает, что его мероприятия переносят слушателей в другой мир. Но, скорее всего, этот мир разный, свой для каждого из слушателей из-за присущего каждому предшествующего опыта, наличных способностей, просто человеческих особенностей. Возможно ли не тодько объединять их в один «другой мир», но и вообще сравнивать? Как будто противореча некоторым (уже приведённым здесь) высказываниям, Ноак утверждает, что «на природе вы действительно ощущаете ценность присутствия здесь и сейчас», «возвышенное чувство своего бытия», тем самым указывая на эту сингулярность опыта каждого. Но далее находим ещё более интересное замечание: «пейзаж делает для собравшихся едва ли не больше, чем музыка» ${ }^{5}$. Что же это означает, о чьём присутствии тогда идёт речь? Ведь и окружающее пространство, и даже организованные звуки - это в строгом смысле не принадлежащая человеку реальность.

Безусловно, эксперименты Ноака проблематизируют связь слушателя, зрителя, субъекта, человека с тем, что его окружает, осуществляя намеренное и неоднократное переключение между его разными каналами восприятия. Более того, звук заменён и заменён как минимум дважды: отрезанные от звуков ландшафта, участники слышат не звук рояля, а трансляцию этого звука через наушники. Это странный жест, и к нему ещё нужно будет вернуться. Именно этот жест, который он изобрёл, позволяет удержаться на грани, не соскальзывая в область не-человеческого и не пытаясь перестроить её для себя как более уютную, что можно вменить в вину устроитедям саунд-парков и описателям soundscapes.

Продолжение этого жеста, окончательное его размыкание более экологично и, соответственно, означает уравнивание воспринимающего со всеми теми объектами, на которых действуют звуковые волны. Фактически именно это следует из позиции М. Томпсон, подкреплённой, разумеется, представлениями о физической природе

\footnotetext{
${ }^{4}$ CM.: http://www.hunternoack.com

${ }^{5}$ https://www.inalandscape.org
} 
звука. Исподьзуя не понятие «музыка» и даже не понятие «звук» (sound), но понятие «sonic», она подчёркивает, что его нужно понимать широко, так как оно вкдючает и пространство, и движение, и технологический процесс, и механизмы, и объекты, и «атмосферу», и формы власти. Как видно, в объём этого понятия вкдючено не тодько не-слышимое (для чедовеческого уха). Вкдючён сюда и «шум», который не квалифицируется как «нежелательный», «громкий» или «слишком сильный», поскольку шуму не нужно никакое (воспринимающее) «я», он может оставаться скрытым из-за привычки слушать так, а не иначе, или по причине недостижения теми или иными звуками порогов восприятия, или нацеленных на пресечение шума механизмов контродя. Свой подход Томпсон называет «этико-аффективным», «децентрирующим слушающего субъекта» [Thompson 2017, 6]. Можно сказать точнее и больше - рассеивающим этого субъекта.

Актуальные дискуссии настоящего времени, выдвинутые недавно объяснительные модели - тёмная экология, плоские онтологии и т. д. - крайне негативны в отношении дюбых центростремительных амбиций. Принимая во внимание глобадьные проблемы космического и квазиприродного (так как зачастую они выступают против использования понятия «природа»), а затем и социального и политического уровней, они настаивают на том, что человеческое восприятие, существование человека как вида в целом - это лишь одна из возможностей, которую не следует преуведичивать. Соответственно, легко представить себе обвинения, которые могут быть направлены в адрес Ноака: его по-прежнему интересует человеческое восприятие; он организует концерты в особых выгороженных зонах; он избавляется от сущностных характеристик этих зон, дабы они не вызывали помех в его акциях; «шум» для него - затруднение, а не источник новых смыслов; он играет музыку, композиторскую классическую музыку, пытаясь нагрузить ею чуждое для неё пространство. Следовательно, Ноак - консерватор, работу которого не следовало бы поддерживать, потому что едва ли она приносит пользу пространству. Более распространены сейчас зеркально выстроенные проекты: художник отправдяется в малоцивидизованные части планеты, чтобы записать их звуки и, подвергнув обработке, организовать «заполнение» ими другого, более доступного пространства. Например, соединив звуки ветра пустыни Атакама и работающих в Исландии гейзеров, запустить этот мощный поток в давно не исподьзуемую по назначению водонапорную башню города Штуер, внутри которой осталась только лестница 
(Stuer sound festival, 2019), и получить на выходе для слушателей почти полностью «природные» компоненты, фактически «естественный» звук.

«Естественный» звук, безусловно, обладает высоким уровнем иммерсивности, быстрее и легче справляясь с задачей «погружения» слушателя, чем, скажем, скорее оперирующее через дистанцию и потому неизбежно «абстрактное» визуальное изображение. В отличие от ауры, передающей «ощущение дали», как бы близок предмет ни был (В. Беньямин), или интенсивности, которая осталась нам как видимый след удалившейся вещи (французская феноменология конца 1980-х - 1990-х гг.), звуковая волна проникает в наши тела непосредственно. Эти тела воспринимают, передают и производят звук как и дюбые тела вокруг, даже если это трудно себе вообразить исходя из (часто всё ещё) ходистских представлений о теле, даже если оно уже понимается как комплексное устройство, включающее компоненты раздичного типа, а не только маклюэнообразные «протезы». Фокусировка на звук означает действительно инвайронментадистское перестроение этого воображения, так как звук и экологически-демократичен (не знает раздичий между теми, на кого направлен), и субстанциален, поскольку часто в работах саунд-арта именно это, «звук как субстанция», оказывает на нас воздействие. Поэтому для звуковых исследований нет «точки зрения», характерной для визуальных исследований: звук распространяется везде. Также и медиальный фокус здесь едва ли подходит, так как человеческие тела не просто проводники звука: если не предполагается выделенной позиции у того или иного производителя звука, вкдючая человеческие, и нет иерархии, вкдючая, например, гендерную, обесцениваются и «крайние» позиции, между которыми распространяется звук. Сторонники sound studies уверены, что слушание (то есть пассивное hearing) - это чувственное сопровождение нашей погружённости в мир, от которого видение, напротив, нас отдаляет. В этом смысле граница между желаемым звуком и нежелательным шумом, между значимым звуком и фоном - это исторически варьирующаяся конструкция. Проведение этой границы как таковой обозначает то, как именно человек воспринимает свою связь с пространством, местом и собственным телом.

При этом показательно, что ухо как таковое в течение уже приблизительно столетия понимается как фактически инженерное устройство, переводящее воздушные вибрации в соответствующие колебания барабанной перепонки. Это важный момент, поскольку 
он показывает, как и чем могут быть связаны «консервативные» проекты Ноака и экологические sound studies: и те и другие используют технические устройства в своём обращении со звуком. Будь то понимание уха как технического инструмента, иди запись недоступных чедовеку звуков, их перевод в воспринимаемый человеком диапазон и воспроизведение, или параллельная исполнению трансляция звука в наушники - каждая из этих операций была бы невозможна без технических устройств. Более того, техника манифестирует условия, которые направляют кажущийся очевидным опыт аудиального погружения.

Однако представдяется, что есть одно важное отличие между акциями Ноака и разработками экологических sound studies. Такое специфическое сочетание визуального, аудиального и технического, которое нашёл Ноак, оказывается условием для продуцирования образов. «Чистый» же звук в терминологии hearing иди sonic, растворяющий чедовеческое восприятие в окружающем пространстве, едва ли объясним при помощи образных рядов. Ноак скромно признаёт, что «природный мир <...> бесконечно сложнее и прекраснее музыки». Но его проект, балансирующий на грани изменённых культурной деятельностью связей с околоприродными ареалами, признаёт нелёгкую и непрямую доступность этих ареалов для взаимодействия. Дело не в том, что музыкант использует два канала чувственного восприятия: как уже говорилось выше, он исподьзует их в превращённом виде, создавая условия для их пересечения, когда они не сливаются и не синтезируются, но перекдючаются иди, если восподьзоваться беньяминовским термином, констелдируют. И это - условие для возникновения образов. Проявлены ли эти усиовия колиективностью? Действительно, остаётся возможность того, что участники надевают наушники в том числе гдядя на соседей, тем самым как будто признавая, что иммерсивность происходящего, уравнительный эффект звукового воздействия вдияет на всех.

Не менее вероятными представдяются сингулярные комбинации образов, которые могут объединяться, а могут и не объединяться в «единый образ» слышимого и видимого. Да и едва ди это обладает первостепенной важностью. Зато помогает понять, что «возвышенное чувство присутствия», которым Ноак характеризует свои нетипичные концерты, - это всего дишь осознавание себя человеческой единицей, происходящее через образ. Но и это уже немало. 


\section{БИБЛИОГРАФИЯ}

Бельтинг 2002 - Бельтинг Х. Образ и культ. История образа до эпохи искусства / Пер. с нем. Москва, 2002.

Мартынов 2005 - Мартынов В. И. Зона Opus Posth, или Рождение новой реальности. Москва, 2005.

Chion 1990 - Chion M. L'audio-vision. Son et image au cinéma. Paris, 1990.

Hoerl 2007 - General ecology. The new ecological paradigm. Ed. by E. Hoerl. London, Oxford, New York, 2007.

Lista 2006 - Lista M. L'CEuvre d'art totale à la naissance des avantgardes, 1908-1914. Paris, 2006.

Mondzain 2010 - Mondzain M.-J. What Does Seeing an Image Mean? // Journal of Visual Culture. 2010. Vol. 9. P. 307-315.

Nancy 2001 - Nancy J.-L. Les Muses. Paris, 2001.

Nancy 2003 - Nancy J.-L. Au fond des images. Paris, 2003.

Oliveros 2010 - Oliveros P. Sounding the Margins: Collected Writings 1992-2009. Kingston, New York, 2010.

Rogozinski 2006 - Rogozinski J. Le moi et la chair. Introduction à l'egoanalyse. Paris, 2006.

Schafer 1977 - Schafer R. M. The Tuning of the World. The Soundscape. New York, 1977.

Thompson 2017 - Thompson M. Beyond Unwanted Sound. Noise, Affect, and Aesthetic Moralism. New York, London, 2017.

Voegelin 2010 - Voegelin S. Listening to Noise and Silence: Towards a Philosophy of Sound Art. New York, 2010.

Voegelin 2014 - Voegelin S. Sonic Possible Worlds: Hearing the Continuum of Sound, 2014.

Материал поступил в редакциию 07.07.2019 